\section{(O) OPEN ACCESS}

\title{
Impact of preprocedural mitral regurgitation upon mortality after transcatheter aortic valve implantation (TAVI) for severe aortic stenosis
}

\author{
M Z Khawaja, ${ }^{1}{ }^{1} 2$ R Williams, ${ }^{1}{ }^{1} 2$ J Hung, ${ }^{1}$ S Arri, ${ }^{1,2} \mathrm{KN}$ Asrress, ${ }^{1,2} \mathrm{~K}$ Bolter, ${ }^{2}$ \\ K Wilson, ${ }^{2}$ C P Young, ${ }^{2}$ V Bapat, ${ }^{2}{ }^{2}$ Hancock, ${ }^{2}$ M Thomas, ${ }^{2}$ S Redwood ${ }^{1,2}$
}

\begin{abstract}
- Additional material is published online only. To view please visit the journal online (http://dx.doi.org/10.1136/ heartjnl-2014-305775).

${ }^{1}$ Cardiovascular Division, King's College, British Heart Foundation Centre of Research Excellence, The Rayne Institute, London, UK

${ }^{2}$ Guy's \& St Thomas' Hospitals NHS Foundation Trust, London, UK
\end{abstract}

\section{Correspondence to} Dr M Z Khawaja, Department of Cardiology, St Thomas' Hospital, Westminster Bridge Road, London SE1 7EH, UK; dr.zeeshan.khawaja@gmail. com

Received 7 March 2014 Revised 13 May 2014 Accepted 23 June 2014 Published Online First 25 August 2014

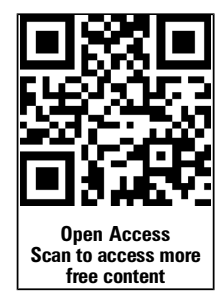

CrossMark

To cite: Khawaja $\mathrm{MZ}$, Williams R, Hung J, et al. Heart 2014;100 1799-1803.

\section{ABSTRACT}

Objective To identify the effects of preprocedural significant mitral regurgitation (MR) and change in MR severity upon mortality after transcatheter aortic valve implantation (TAVI) using the Edwards SAPIEN system.

Methods A retrospective analysis of 316 consecutive patients undergoing TAVI for aortic stenosis at a single centre in the UK between March 2008 and January 2013. Patients were stratified into two groups according to severity of MR: $\geq$ grade 3 were classed as significant and $\leq$ grade 2 were non-significant. Change in MR severity was assessed by comparison of baseline and 30-day echocardiograms.

Results 60 patients had significant MR prior to TAVI (19.0\%). These patients were of higher perioperative risk (logistic EuroScore $28.7 \pm 16.6 \%$ vs $20.3 \pm 10.7 \%$, $\mathrm{p}=0.004$ ) and were more dyspnoeic (New York Heart Association class IV $20.0 \%$ vs $7.4 \%, p=0.014$ ). Patients with significant preprocedural MR displayed greater 12 -month and cumulative mortality $(28.3 \%$ vs $20.2 \%$, log-rank $p=0.024)$. Significant MR was independently associated with mortality (HR 4.94 (95\% Cl 2.07 to 11.8$), p<0.001)$. Of the 60 patients with significant MR only $47.1 \%$ had grade 3-4 MR at 30 days $(p<0.001)$. Patients in whom MR improved had lower mortality than those in whom it deteriorated (log-rank $p=0.05$ ).

Conclusions Significant MR is frequently seen in patients undergoing TAVI and is independently associated with increased all-cause mortality. Yet almost half also exhibit significant improvements in MR severity. Those who improve have better outcomes, and future work could focus upon identifying factors independently associated with such an improvement.

\section{INTRODUCTION}

Transcatheter aortic valve implantation (TAVI) to treat severe, calcific aortic stenosis (AS) has been shown to be both feasible and beneficial in those at prohibitive or high risk for surgical aortic valve replacement (sAVR) risk. ${ }^{12}$

Previous surgical series have frequently identified mitral regurgitation (MR) in association with AS. ${ }^{3-5}$ Combined surgical intervention is associated with increased mortality and morbidity. ${ }^{4-6}$ Current guidelines therefore suggest careful multidisciplinary evaluation and that, in the absence of morphological abnormalities, surgery for non-severe $\mathrm{MR}$ is not required, as relief of left ventricular pressure by sAVR resolves matters. There is no specific guidance regarding the management of more significant MR and the authors recognised the lack of data in the field. ${ }^{7}$

The issue of how to approach combined AS and MR prior to TAVI is complicated by the lack of a feasible technique for combined intervention. There has been discord in observational assessments of the effects of significant MR upon outcome after TAVI using both balloon-expandable and self-expanding systems. ${ }^{8-15}$ We sought to identify the prognostic impact of both significant MR and change in MR severity in patients undergoing TAVI using the balloon-expandable Edwards SAPIEN/SAPIEN XT bioprosthesis.

\section{METHODS}

We performed a retrospective analysis of 316 consecutive, successful implantations of the Edwards bioprosthesis at St. Thomas' Hospital, London, from March 2008 to January 2013. Multimodality assessments were performed as previously described and cases reviewed at a multidisciplinary team meeting. ${ }^{16}$ TAVI was performed using transfemoral, transapical or transaortic routes.

Patients were prospectively enrolled onto a dedicated database of patient demographics, characteristics, procedural results and long-term outcome. MR was graded by either transthoracic or transoesophageal echocardiography. As per current guidelines, this involved assessment of valve morphology, colour Doppler and continuous-wave Doppler of the regurgitant jet, vena contracta width, upstream venous flow, regurgitant volume and effective orifice area (where available). ${ }^{17}$ All scans were performed by British Society of Echocardiography accredited echocardiographers with final adjudication by a consultant cardiologist specialising in cardiac imaging. MR was deemed 'significant' if moderate or severe ( $\geq$ grade 3 ). Mortality data were obtained from the Office of National Statistics, UK.

Data analysis was performed using SPSS V.21.0 (IBM Corp., New York, USA) and PRISM V.6 (Graphpad Software, California, USA). Survival curves were created using the Kaplan-Meier method. Univariate Cox proportionate hazards modelling was performed using an unadjusted model for each covariate, and we then constructed a multivariate model using a forward elimination method and entry criteria of $\mathrm{p} \leq 0.05$. 


\section{RESULTS}

We analysed 316 patients who underwent TAVI for severe AS using either the Edwards SAPIEN or SAPIEN XT bioprostheses. In total, 60/316 (19.0\%) patients were identified as having moderate-to-severe MR. Baseline characteristics are summarised in table 1. Patients with significant MR had higher perioperative risk according to logistic EuroScore $(28.7 \pm 16.6 \%$ vs 20.3 $\pm 10.7 \%, p=0.004)$ and Society of Thoracic Surgeons (STS) score $(7.7 \pm 3.7$ vs $5.7 \pm 3.1, \mathrm{p}<0.001)$. They also had more severe dyspnoea (New York Heart Association IV in $20.0 \%$ vs $7.4 \%, \mathrm{p}=0.014)$, poorer LVEF $(44.0 \pm 14.6 \%$ vs $50.4 \pm 11.8 \%$, $\mathrm{p}=0.004)$ and more frequent significant ( $\geq$ grade 3$)$ aortic or tricuspid regurgitation (TR) $(28.3 \%$ vs $12.1 \% \quad(p=0.046)$ and $28.3 \%$ vs $8.9 \%(\mathrm{p}<0.001)$, respectively).

\section{Procedural outcomes}

Procedural success was $100 \%$ in both groups. Efficacy of the TAVI regardless of MR was manifest by the improvement in peak transaortic gradient at follow-up (figure 1). Patients with significant preprocedural MR had higher rates of postprocedural haemofiltration $(18.3 \%$ vs $7.0 \%, \mathrm{p}=0.006)$, although there was no difference in length of intensive care stay $(3.5 \pm 6.8$ days vs $3.2 \pm 10.2$ days, $\mathrm{p}=0.840$ ).

\section{Mortality}

Kaplan-Meier analysis revealed that patients with significant preprocedural MR had higher all-cause mortality $(28.3 \%$ vs $20.2 \%$ at 12 months) and significantly divergent mortality plots $(\log$-rank $\mathrm{p}=0.023)$ (see figure 2A). Patients in whom MR deteriorated had a poorer outcome than those with an improvement

Table 1 Patient demographics

\begin{tabular}{|c|c|c|c|}
\hline & $\begin{array}{l}\text { No significant } \\
\text { MR } \\
n=256\end{array}$ & $\begin{array}{l}\text { Significant } \\
M R \\
n=60\end{array}$ & $\mathrm{p}$ Value \\
\hline Age (years, mean $\pm S D$ ) & $81.8 \pm 8.9$ & $83.2 \pm 7.4$ & 0.288 \\
\hline Male \% (n) & $57.8 \%(148)$ & $55.0 \%(33)$ & 0.692 \\
\hline Peripheral vascular disease & $11.3 \%(29)$ & $18.3 \%(11)$ & 0.142 \\
\hline Chronic respiratory disease & $21.5 \%(55)$ & $23.4 \%(14)$ & 0.952 \\
\hline Pulmonary hypertension & $19.0 \%(48)$ & $30.0 \%(18)$ & 0.060 \\
\hline Prior revascularisation & $39.5 \%(101)$ & $41.7 \%(25)$ & 0.753 \\
\hline Logistic EuroScore (\%) & $20.3 \pm 10.7$ & $28.7 \pm 16.6$ & 0.004 \\
\hline STS & $5.7 \pm 3.1$ & $7.7 \pm 3.7$ & $<0.001$ \\
\hline \multicolumn{4}{|l|}{ New York Heart Association } \\
\hline Class I & $2.3 \%(6)$ & $5.0 \%(3)$ & 0.014 \\
\hline Class II & $29.7 \%(76)$ & $21.1 \%(13)$ & \\
\hline Class III & $60.5 \%(155)$ & $53.3 \%(32)$ & \\
\hline Class IV & $7.4 \%(19)$ & $20.0 \%(12)$ & \\
\hline $\operatorname{LVEF}(\%)$ & $50.4 \pm 11.8$ & $44.0 \pm 14.6$ & 0.004 \\
\hline Peak AV gradient $(\mathrm{mm} \mathrm{Hg})$ & $72.0 \pm 23.7$ & $72.0 \pm 54.6$ & 0.995 \\
\hline Aortic valve area $\left(\mathrm{cm}^{2}\right)$ & $0.68 \pm 0.24$ & $0.69 \pm 0.30$ & 0.749 \\
\hline Aortic regurgitation $\geq$ grade 3 & $12.1 \%(31)$ & $28.3 \%(16)$ & 0.046 \\
\hline $\begin{array}{l}\text { Tricuspid regurgitation } \\
\geq \text { grade } 3\end{array}$ & $9.0 \%(23)$ & $28.4 \%(17)$ & $<0.001$ \\
\hline eGFR $\left(\mathrm{mL} / \mathrm{kg} / 1.73 \mathrm{~m}^{2}\right)$ & $57.0 \pm 22.2$ & $52.5 \pm 20.7$ & 0.149 \\
\hline \multicolumn{4}{|l|}{ Site } \\
\hline Transapical & $35.9 \%(92)$ & $36.7 \%(22)$ & 0.994 \\
\hline Transfemoral & $45.7 \%(117)$ & $45.0 \%(27)$ & \\
\hline Transaortic & $18.4 \%(47)$ & $18.3 \%(11)$ & \\
\hline
\end{tabular}

eGFR, estimated glomerular filtration rate; MR, mitral regurgitation; STS, Society of

Thoracic Surgeons. in MR (log-rank $\mathrm{p}=0.05$, see figure $2 \mathrm{~B}$ ). We found no difference between the demographics of these groups except a higher rate of pulmonary disease in those MR improved (see online supplementary table S1).

\section{Changes in MR severity}

When we consider the overall study population, there was no difference in the distribution of MR severity between the pre-TAVI, 30-day and 12-month time-points. However, only $47.1 \%$ of the 60 patients with significant preprocedural MR had grade 3-4 MR at 30 day (McNemar's test $p<0.001$ ), with no significant difference at $12 \mathrm{~m}$. In those patients without baseline significant $\mathrm{MR}$, there was no significant change in the distribution $(p=0.07) .40$ patients had significant TR at baseline (ie, grade $\geq 3$ ). Thirty-seven had 30 day echo data available, and of these only $13(35.1 \%)$ had significant TR $(\mathrm{p}<0.001)$.

In the 60 patient cohort with significant MR, the aetiology was organic in $83.3 \%$ of patients whose MR deteriorated and $72.4 \%$ in those in whom MR improved $(p<0.001)$.

The changes in LVEF are summarised in table 2. Patients undergoing TAVI experienced an improvement in LVEF $(p<0.001)$, driven by an improvement in those patients without significant MR $(p<0.001)$. Those with significant MR did not improve $(\mathrm{p}=0.219)$.

Multivariate Cox proportional hazards modelling revealed that significant preprocedural $\mathrm{MR}$ had an independent association with mortality (HR 4.94 (95\% CI 2.07 to 11.76), $\mathrm{p}<0.001)$ as did estimated glomerular filtration rate (HR 0.97 (95\% CI 0.95 to 0.99 ), $\mathrm{p}=0.001$ ). Significant $\mathrm{TR}$-present in 40 patients $(12.7 \%)$-reached significance in the univariate analysis but not the multivariate.

\section{DISCUSSION}

Our study confirms that preprocedural significant MR has an independent association with mortality after TAVI using the Edwards bioprosthesis-but also that significant regurgitation also improves in many of these patients. Given that improvement and that the mortality in the MR cohort is still reassuringly smaller than that of TAVI candidates treated medically, ${ }^{1}$ TAVI should not be denied to these patients on the basis of MR alone.

Significant MR at the time of sAVR is associated with an increased risk of adverse outcome ${ }^{4} 5$ and current guidelines

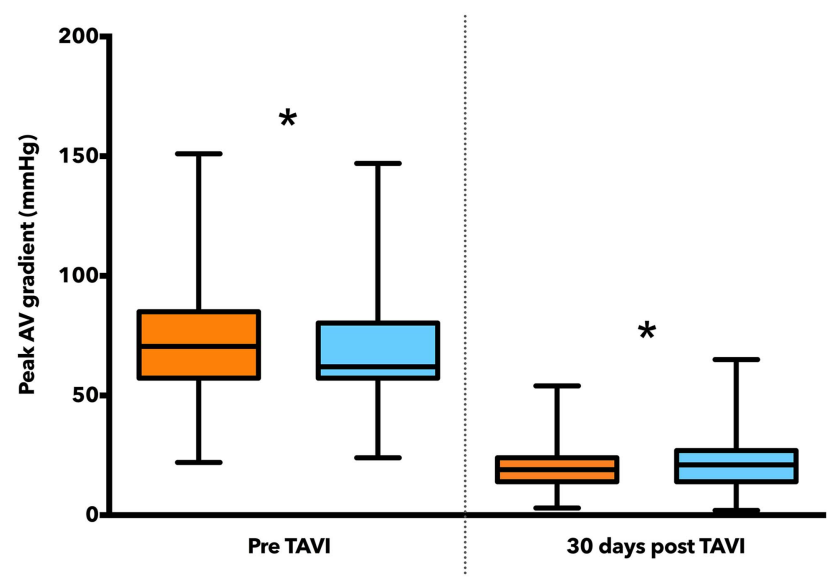

Figure 1 Peak aortic valve gradients. Significant MR is denoted by orange, non-significant MR by blue. * $p$ is non-significant (ie, e>0.05). $M R$, mitral regurgitation; TAVI, transcatheter aortic valve implantation. 
Figure 2 (A) Kaplan-Meier curve demonstrating the increased cumulative mortality of significant preprocedural mitral regurgitation (MR). (B) Kaplan-Meier curve demonstrating the effects of change in MR severity after transcatheter aortic valve implantation upon mortality.
A

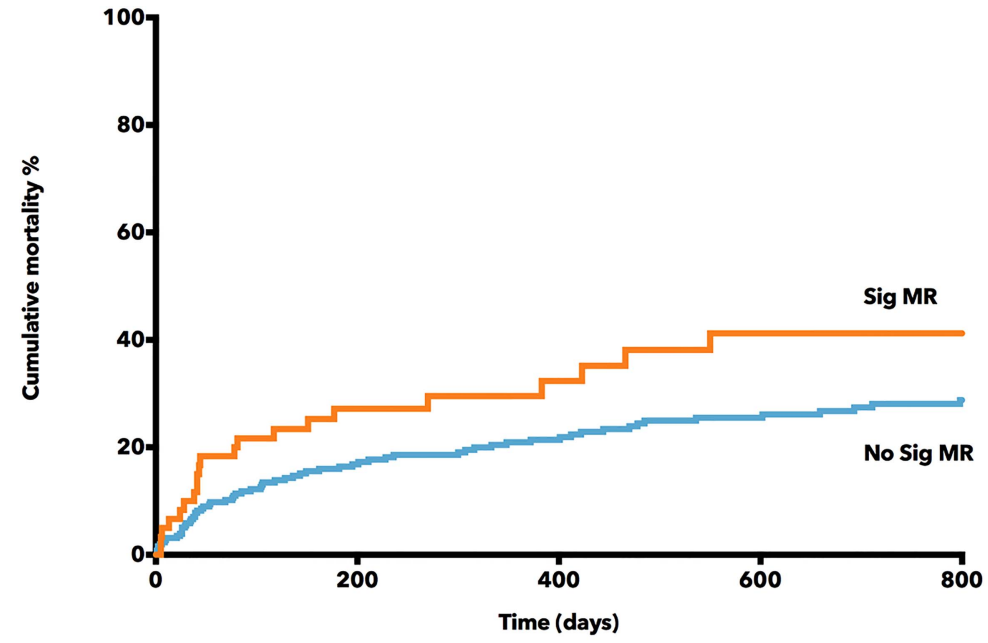

Patients at risk
Significant MR

No significant MR

191

36

B

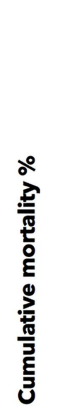

Patients at risk

MR worse

MR better

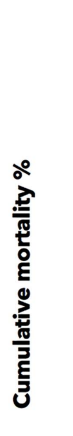

recommend treatment of both conditions if the valvular haemodynamics suggest significant disease in both. ${ }^{7}$ Concomitant MR with AS is well described in the surgical literature and has also been noted in patients with TAVI. ${ }^{4} 91218$

Functional MR is frequently seen in dilated cardiomyopathy and increases mortality. ${ }^{19} 20$ It is caused by distortion of the LV and papillary muscle geometry, displacing the mitral valve leaflets (MVL) below the plane of the MV annulus: when there is

Table 2 Changes in LVEF

\begin{tabular}{llll}
\hline & Overall & Significant MR & No significant MR \\
\hline Baseline LVEF (\%) & $49.1 \pm 12.7$ & $43.7 \pm 15.0$ & $50.4 \pm 11.7$ \\
30d LVEF (\%) & $52.2 \pm 12.6$ & $45.7 \pm 13.5$ & $53.9 \pm 11.9$ \\
& $\mathrm{p}<0.001$ & $\mathrm{p}=0.219$ & $\mathrm{p}<0.001$ \\
\hline
\end{tabular}

MR, mitral regurgitation insufficient MVL area to compensate, the valve apparatus is rendered incompetent. ${ }^{20-25}$ Leaflet thickness and area increase in response to abnormal loading with increased tension during systole $^{21}$ through greater expression of collagen and aminoglycosans rendering them less compliant. ${ }^{26-28}$

Recently, results from a large Italian CoreValve registry have suggested a higher 1-month mortality in the severe and moderate MR groups than those with mild or no MR $(11 \%$ vs $9 \%$ vs $5 \%$, respectively), extending to the 1 -to- 12 -month time period (17\% vs $12 \%$ vs $10 \%)$. The presence of greater-than-mild MR increased the risk of death by almost threefold, and $8.4 \%$ of patients with less-than-mild MR suffered a deterioration in their grade of MR. ${ }^{12}$ The design of the more intrusive CoreValve prosthesis may cause greater interference of the anterior MVL. ${ }^{29}$

Toggweiler and colleagues have previously noted an increase in 30-day mortality in patients with moderate-severe MR receiving the Edwards device (adjusted HR 2.10, p=0.02)however, mortality beyond 30 days was similar. ${ }^{8}$ An 'as-treated' 
analysis of cohort A patients from the PARTNER trial found that preprocedural MR had no effect upon mortality after balloon-expandable TAVI but did adversely impact outcome after sAVR. ${ }^{9}$ Severe MR was a contraindication to enrolment into the PARTNER trial-though in the subsequent analysis, seven patients $(2.3 \%)$ did have severe MR. In the primary analysis of the PARTNER B cohort, there was a trend to favour TAVI above medical therapy in patients with moderate-severe MR $\left(\mathrm{P}_{\text {interaction }}=0.09\right) .{ }^{1}$ Recently, two studies analysing atrioventricular regurgitation and transapical TAVI have shown a similar improvement in MR but no long-term effect upon mortality ${ }^{13}{ }^{14}$-though one noted a fourfold increase in risk of in-hospital death. ${ }^{14}$ Sixty-seven per cent of patients in a study by Hutter et al demonstrated an improvement in MR after TAVI. While those with moderate-severe MR had higher $12 \mathrm{~m}$ mortality $(30.2 \%$ vs $21.2 \%)$, it did not reach statistical significance $(\mathrm{p}=0.068){ }^{15}$

Improvement in the degree of MR after TAVI has been associated with the absence of pulmonary hypertension and atrial fibrillation, ${ }^{8} 12$ mean aortic valve gradient $>40 \mathrm{~mm} \mathrm{Hg}^{8}$ and functional MR. ${ }^{8}{ }^{12}$ Similarly after sAVR functional MR has been associated with improvement in the severity of MR. ${ }^{4}$ Functional MR relies on an incompetent orifice and sufficient systolic gradient between the LV and left atrium. LV dysfunction and remodelling and increased LV afterload as seen in AS can lead to these morphological and haemodynamic changes. LV wall stress and ejection pressure have been shown to improve after sAVR, ${ }^{30}$ which may explain some of the beneficial effects of aortic valve intervention. Our own data are consistent with the literature and suggest that patients whose significant MR improved had higher rates of functional MR, suggesting that there may be a 'threshold' LV pressure causing MR in an abnormal ventricle/ valve unit that TAVI may improve. Given existing data detailed above, perhaps caution should be exhibited in patients with organic MR and sequelae such as atrial fibrillation and pulmonary hypertension. However, such a recommendation would require studies larger by orders of magnitude than those currently in the literature.

\section{LIMITATIONS}

The data for our study were gathered prospectively into a TAVI patient database. However, the analyses were performed post hoc using definitions devised after the initiation of data collection and are limited by the available parameters. The study, like all registry data, is subject to the effects of possible confounders and bias in its design. The limited size of the study means that differences between patients with/without significant preprocedural MR or with/without improved MR may not have reached significance due to limited power. Finally, the raw quantitative data used in the assessment of MR severity were not always available and so could not be included for analysis.

\section{CONCLUSION}

Previous data regarding the effects of preprocedural MR upon outcome after balloon-expandable TAVI have been inconsistent. We have demonstrated that significant MR does have a significant effect upon mortality after TAVI, but the magnitude of this change would appear to be less significant than the potential benefits of TAVI. As such, MR should not present an absolute contraindication to TAVI. Given the deleterious effect of worsening of MR severity, we suggest that larger collaborative studies are necessary to identify factors associated with risk of deterioration.

\section{Key messages}

What is already known on this subject?

Mitral regurgitation (MR) is often found in patients with calcific aortic stenosis and current guidelines suggest it can be left untreated at the time of surgical aortic valve replacement unless severe. MR has also been described in high-risk patients undergoing transcatheter aortic valve implantation (TAVI), but there is disagreement regarding its impact upon outcome.

\section{What might this study add?}

Our study has found an independent association between 'significant' (ie, moderate-severe) MR and the risk of death after TAVI, while confirming that there is also a significant improvement in the degree of MR seen after TAVI. Mortality rates seen in patients with significant MR are considerably lower than we would expect in patients from this cohort receiving only medical therapy. Patients with significant MR who experience an improvement have higher rates of functional MR rather than organic disease and have lower mortality than those in whom MR worsens. We also found a reduction in significant tricuspid regurgitation.

\section{How might this impact on clinical practice?}

While clinicians assessing patients for TAVI should be mindful of the increased risk of patients with significant MR, it should not be considered a contraindication. But careful examination of the severity and aetiology of the MR is necessary in preprocedural selection and planning. Given the deleterious effects of worsening MR, further collaborative work is necessary to identify those at risk to improve safety for patients with MR undergoing TAVI.

Contributors All the authors fulfil relevant criteria for authorship regarding design, analysis, interpretation, drafting, revision and approval of the study and manuscript.

Funding MZK (FS/12/15/29380), RW (FS/11/90/29087) and KNA (FS/11/43/28760) receive British Heart Foundation Clinical Research Training Fellowship funding.

Competing interests MZK, MT and SR have received research funding from, and CPY, VB, MT and SR are proctors for Edwards LifeSciences (Irvine, California, USA).

Provenance and peer review Not commissioned; externally peer reviewed.

Open Access This is an Open Access article distributed in accordance with the Creative Commons Attribution Non Commercial (CC BY-NC 4.0) license, which permits others to distribute, remix, adapt, build upon this work non-commercially, and license their derivative works on different terms, provided the original work is properly cited and the use is non-commercial. See: http://creativecommons.org/ licenses/by-nc/4.0/

\section{REFERENCES}

1 Leon MB, Smith CR, Mack M, et al. Transcatheter aortic-valve implantation for aortic stenosis in patients who cannot undergo surgery. $N$ Engl J Med 2010;363:1597-607.

2 Kodali SK, Williams MR, Smith CR, et al. Two-year outcomes after transcatheter or surgical aortic-valve replacement. N Engl J Med 2012;366:1686-95.

3 Asimakopoulos G, Edwards MB, Taylor KM. Aortic valve replacement in patients 80 years of age and older: survival and cause of death based on 1100 cases: collective results from the UK Heart Valve Registry. Circulation 1997;96:3403-8.

4 Barreiro CJ, Patel ND, Fitton TP, et al. Aortic valve replacement and concomitant mitral valve regurgitation in the elderly: impact on survival and functional outcome. Circulation 2005; 112:1443-7.

5 Harling L, Saso S, Jarral OA, et al. Aortic valve replacement for aortic stenosis in patients with concomitant mitral regurgitation: should the mitral valve be dealt with? Eur J Cardiothorac Surg 2011:40:1087-96. 
6 Mueller XM, Tevaearai HT, Ruchat $\mathrm{P}$, et al. Perioperative morbidity and mortality in combined aortic and mitral valve surgery. J Heart Valve Dis 1997,

6:387-94.

7 Vahanian A, Alfieri O, Andreotti F, et al.; Authors/Task Force Members. Guidelines on the management of valvular heart disease (version 2012): The Joint Task Force on the Management of Valvular Heart Disease of the European Society of Cardiology (ESC) and the European Association for Cardio-Thoracic Surgery (EACTS). Eur Heart J 2012;33:2451-96.

8 Toggweiler S, Boone RH, Rodés-Cabau J, et al. Transcatheter aortic valve replacement: outcomes of patients with moderate or severe mitral regurgitation. J Am Coll Cardiol 2012;59:2068-74.

9 Barbanti M, Webb JG, Hahn RT, et al. Impact of preoperative moderate/severe mitral regurgitation on 2-year outcome after transcatheter and surgical aortic valve replacement: insight from the Placement of Aortic Transcatheter Valve (PARTNER) Trial Cohort A. Circulation 2013;128:2776-84.

10 Hekimian G, Détaint D, Messika-Zeitoun D, et al. Mitral regurgitation in patients referred for transcatheter aortic valve implantation using the Edwards Sapien prosthesis: mechanisms and early postprocedural changes. J Am Soc Echocardiogr 2012;25:160-5.

11 Giordana F, Capriolo M, Frea $S$, et al. Impact of TAVI on mitral regurgitation: a prospective echocardiographic study. Echocardiography 2013;30:250-7.

12 Bedogni F, Latib A, De Marco F, et al. Interplay between mitral regurgitation and transcatheter aortic valve replacement with the CoreValve Revalving System: a multicenter registry. Circulation 2013;128:2145-53.

13 Wilbring $M$, Tugtekin S-M, Ritzmann $M$, et al. Transcatheter aortic valve implantation reduces grade of concomitant mitral- and tricuspid valve regurgitation and pulmonary hypertension. Eur J Cardiothorac Surg 2014:ezu037.

14 Haensig M, Holzhey DM, Borger MA, et al. Improved mitral valve performance after transapical aortic valve implantation. Ann Thorac Surg 2014;97:1247-54.

15 Hutter A, Bleiziffer S, Richter V, et al. Transcatheter aortic valve implantation in patients with concomitant mitral and tricuspid regurgitation. Ann Thorac Surg 2013;95:77-84.

16 Khawaja M, Thomas M, Joshi A, et al. The effects of VARC-defined acute kidney injury after transcatheter aortic valve implantation (TAVI) using the Edwards bioprosthesis. Eurolntervention 2012;8:563-70. EIJV8I5A87

17 Lancellotti P, Moura L, Pierard LA, et al. European Association of Echocardiography recommendations for the assessment of valvular regurgitation. Part 2: mitral and tricuspid regurgitation (native valve disease). Eur J Echocardiogr 2010;11:307-32.
18 D'Onofrio A, Gasparetto V, Napodano M, et al. Impact of preoperative mitral valve regurgitation on outcomes after transcatheter aortic valve implantation. Eur J Cardiothorac Surg 2012;41:1271-6; discussion 1276-7.

19 Rossi A, Dini FL, Faggiano P, et al. Independent prognostic value of functional mitral regurgitation in patients with heart failure. A quantitative analysis of 1256 patients with ischaemic and non-ischaemic dilated cardiomyopathy. Heart 2011;97:1675-80.

20 Park S-M, Park SW, Casaclang-Verzosa G, et al. Diastolic dysfunction and left atrial enlargement as contributing factors to functional mitral regurgitation in dilated cardiomyopathy: data from the Acorn trial. Am Heart J 2009;157:762.e3-10.

21 Chaput M, Handschumacher MD, Tournoux F, et al. Mitral leaflet adaptation to ventricular remodeling: occurrence and adequacy in patients with functional mitral regurgitation. Circulation 2008;118:845-52.

22 Sabbah HN, Kono T, Rosman H, et al. Left ventricular shape: a factor in the etiology of functional mitral regurgitation in heart failure. Am Heart J 1992;123:961-6.

23 Otsuji $Y$, Handschumacher MD, Schwammenthal $E$, et al. Insights from three-dimensional echocardiography into the mechanism of functional mitral regurgitation: direct in vivo demonstration of altered leaflet tethering geometry. Circulation 1997;96:1999-2008.

24 Komeda M, Glasson JR, Bolger AF, et al. Geometric determinants of ischemic mitral regurgitation. Circulation 1997;96(9 Suppl):II-128-33.

25 Yiu SF, Enriquez-Sarano M, Tribouilloy C, et al. Determinants of the degree of functional mitral regurgitation in patients with systolic left ventricular dysfunction: a quantitative clinical study. Circulation 2000;102:1400-6.

26 Kunzelman KS, Quick DW, Cochran RP. Altered collagen concentration in mitral valve leaflets: biochemical and finite element analysis. ATS 1998;66:S198-205.

27 Grande-Allen KJ, Borowski AG, Troughton RW, et al. Apparently normal mitral valves in patients with heart failure demonstrate biochemical and structural derangements: an extracellular matrix and echocardiographic study. J Am Coll Cardiol 2005:45:54-61.

28 Grande-Allen KJ, Barber JE, Klatka KM, et al. Mitral valve stiffening in end-stage heart failure: evidence of an organic contribution to functional mitral regurgitation. J Thorac Cardiovasc Surg 2005;130:783-90.

29 De Chiara B, Moreo A, De Marco F, et al. Influence of CoreValve ReValving System implantation on mitral valve function: an echocardiographic study in selected patients. Catheter Cardiovasc Interv 2011;78:638-44.

30 Harpole DH, Gall SA, Wolfe WG, et al. Effects of valve replacement on ventricular mechanics in mitral regurgitation and aortic stenosis. ATS 1996;62:756-61. 